\title{
OBRAS ATRIBUIDAS E INÉDITAS DE JUAN BAUTISTA VÁZQUEZ EL VIEJO Y SU TALLER EN EL EN EL REINO DE SEVILLA.
}

\author{
JESÚS PORRES BENAVIDES \\ Universidad Rey Juan Carlos. Madrid
}

\begin{abstract}
Resumen
En el presente artículo, se da a conocer varias obras inéditas en la antigua diócesis sevillana, atribuidas al escultor Juan Bautista Vázquez "el viejo" (San Sebastián de la capilla de San Francisco de Carmona y San Antonio Abad de la iglesia de Santa María de Carmona), que muestran rasgos semejantes con otras obras conocidas. Aparte, se analizará la imagen de San Juan Evangelista de la capilla del Dulce Nombre de Sevilla que, aunque fue tratada en artículos anteriores, no ha sido suficientemente estudiada. También se incluyen, dentro de la producción cercana al maestro, obras como las imágenes de Santa Ana, Santa Bárbara y un Dios Padre que pueden estar en la producción de los seguidores de Vázquez. Además del método comparativo, que ha permitido identificar estas imágenes, se ha procedido al análisis de las distintas iconografías.
\end{abstract}

Palabras clave

Juan Bautista Vázquez “el viejo”, Escultura manierista sevillana, Iconografía cristiana, San Sebastián, Dios Padre, San Antonio abad, San Juan Evangelista y Santa Ana.

\section{WORKS ASSIGNED AND UNEDITED BY JUAN BAUTISTA VÁZQUEZ EL VIEJO AND HIS WORKSHOP IN THE IN THE KINGDOM OF SEVILLA.}

\begin{abstract}
In this article several new works to be found in the old diocese of Seville, they are attributed to the sculptor Juan Bautista Vázquez "el Viejo" (for example, the images of Saint Sebastian which is located in the Church of San Francisco of Carmona and of Saint Anthony Abbot of Santa Maria Church in Carmona). These pieces show features which are similar to other known works of this sculptor. This article also studies the images of St. John the Evangelist in the Dulce Nombre Chapel of Seville. Although this work has been dealt with in previous articles, to date it has not been sufficiently studied. An analysis of three further works is also included, namely, Saint Anne, Saint Barbara and God the Father, because they are closely related to artists who moved in the same circle as Vasquez. Besides this comparative method, which has allowed me to identify the various works, I have also undertaken an analysis of different iconographies.

$$
\text { Key Words }
$$

Juan Bautista Vázquez “el Viejo”, Sevillian mannerist sculpture, Christian Iconography. Saint Sebastian, God Father, Saint Anthony Abbot Saint John Evangelist and Saint Ane.
\end{abstract}

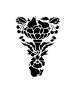

Ucoarte. Revista de Teoría e Historia del Arte, 4, 2015, pp.9-23. ISSN: 2255-1905 


\section{Introducción}

En los últimos años se ha procedido a una revisión de las atribuciones de esculturas andaluzas del llamado Siglo de Oro en general, y en concreto, de la de algunos escultores como, Juan Bautista Vázquez, tanto en Andalucía como en América1. Vázquez, "el viejo" será el que formule las bases de esta escuela ${ }^{2}$ junto a otros artistas venidos también de Castilla a Sevilla. Es sobre 1570 cuando puede considerarse a Vázquez como jefe de esta incipiente escuela.

Siendo Vázquez el escultor activo más importante del momento en Sevilla, es lógico que su obra y la escuela que en torno a él se formó tuviera una notable influencia en Andalucía occidental y en América. En este sentido, en los últimos años se ha localizado un número importante de sus obras fuera del marco estrictamente sevillano. Algunos estudios de los profesores Fernando Cruz Isidoro ${ }^{3}$ o Francisco Herrera García han aumentado su producción en zonas como la provincia de Cádiz o en algunas partes de América latina como Colombia respectivamente.

Juan Bautista Vázquez, "el Viejo" o "el mayor", como en su época lo distinguen los documentos de su hijo homónimo y también escultor Juan Bautista Vázquez "el Joven”, representa quizás uno de los mejores exponentes de la imaginería renacentista de la segunda mitad del XVI en Sevilla. Se le considera el padre de una escuela de imaginería local, enraizada con artistas de gran talento como son Jerónimo Hernández, Gáspar del Águila o Miguel Adán, por citar a algunos. Además, se distinguió por sus labores como retablista, pintor y grabador.

Vázquez organiza en Sevilla su taller, donde tendría como aprendices a Jerónimo Hernández ${ }^{4}$ que estuvo con él desde Toledo- a Melchor Turín, granadino (1563) ${ }^{5}$, y al portugués Amador López, que luego emigraría al Perú. Turín alcanzará el grado de escultor y colabora con el maestro en MedinaSidonia y con el "Mozo" en San Jerónimo de Granada. Como comenta el profesor Valiñas López, poco se conoce todavía de este último escultor ${ }^{6}$.

En su desplazamiento a Sevilla, le acompañaron como oficiales su cuñado Juan de Oviedo, "el viejo" y el colaborador de éste, Miguel Adán, que desde 1553 hasta 1557 estará con Vázquez en Toledo y después marchara con él a Sevilla ${ }^{7}$. También trabajara junto al abulense, Gaspar del Águila, hijo del también escultor y pintor Juan del Águila. En su testamento cita también como oficiales a "Alberto y Zapata".

Recientemente, el profesor Fernando Cruz Isidoro, ha demostrado que Gaspar Núñez Delgado fue primero discípulo y colaborador de Vázquez "el viejo" y no de Jerónimo Hernández como se venía creyendo9.

Vázquez, también se relaciona con los artistas locales, a los que sirve de fiador, perito e incluso albacea testamentario. Todo este refuerzo de artistas constituyeron una amplia y penetrante vanguardia que expandió por la ciudad y por su área de influencia del Renacimiento italiano.

1 Gila Medina/Herrera García, 2010 o Porres Benavides, 2014: 182-194. También creo que se ha contribuido al conocimiento en general de Bautista Vázquez y en concreto de su técnica con la publicación de la tesis doctoral: Porres Benavides, 2014 (2).

2 Bernales Ballesteros/García de la Concha, 1986: 29.

${ }^{3}$ Cruz Isidoro, 2006 y 2012.

4 Palomero da a conocer el contrato fechado en 1555 en Ávila, por el que Hernández "se compromete como aprendiz para Bautista Vázquez, entallador e imaginario, vecino de Toledo". Por el cual "Bautista Vázquez... digo que acepto y recibo en mi casa a y oficio al dicho Gerónimo Hernández por el dicho tiempo de los seis años que de los dichos ocho años faltan por correr", pues dos años antes habían suscrito un compromiso verbal por el que ingresaba en el taller, cosa infrecuente, pues lo habitual era un contrato desde el principio en Palomero Páramo, 1981: 139-142.

${ }^{5}$ En octubre de 1563, Melchor de Torines, natural de Granada, de trece años de edad, entraba de aprendiz con Vázquez durante cinco años en López Martínez, 1932: 141.

6 "Un nombre con atisbos de medianía” en Valiñas López, 2010:27.

${ }^{7}$ Cursó aprendizaje en Cuenca con Esteban Jamete, para pasar en 1553 al obrador toledano de Vázquez el Viejo en Rokiski Lázaro, 2010: 27.

${ }^{8}$ Palomero Páramo, 1981: 169.

${ }^{9}$ Cruz Isidoro, 2006:7. El 10 de noviembre de 1576, era oficial en el taller de Vázquez, previo a su relación con Jerónimo Hernández en Alonso Moral, 2010:336. 


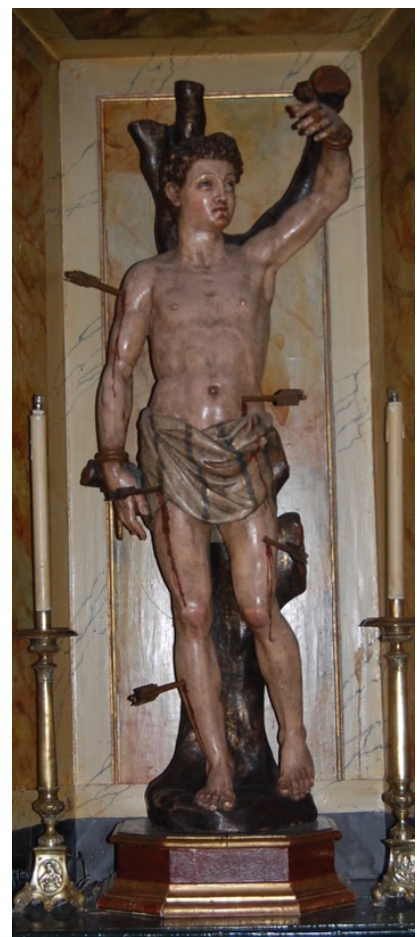

Fig.1. Imagen de San Sebastián. Capilla de San Sebastián, Carmona (Sevilla). CJesús Porres Benavides.

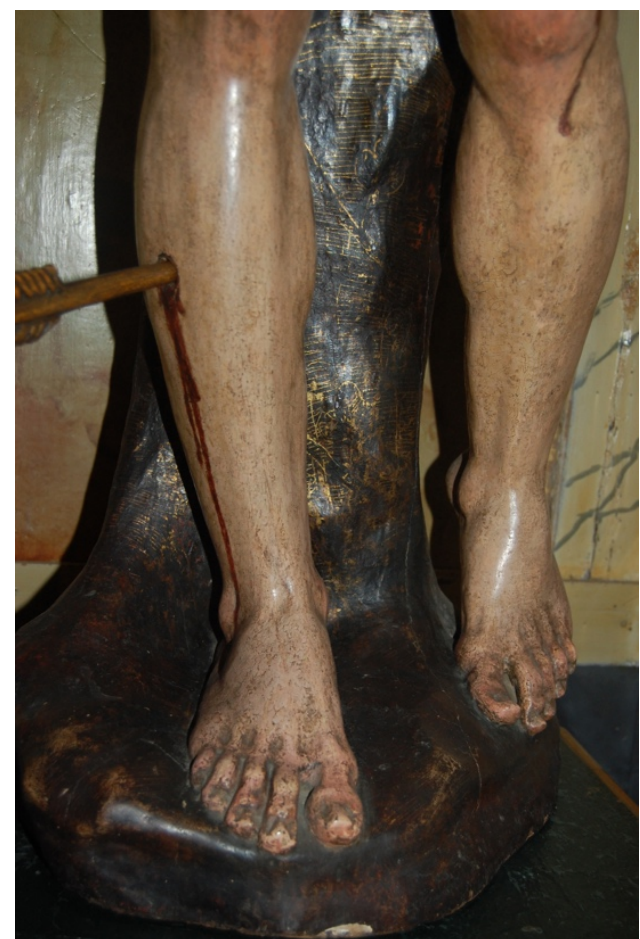

Fig.2. Por menor de los pies. Imagen de San Sebastián. Capilla de San Sebastián, Carmona (Sevilla). C) Jesús Porres Benavides.

Es en el periodo que abarca de los años 1560-1580 cuando se observa una actividad más frenética. Una actividad que no tendrá como único epicentro Sevilla sino otros puntos de la geografía andaluza como Jerez, Málaga, Écija o algunos pueblos de Córdoba o Huelva e incluso envíos a América. Después, en la década de 1580 se observa una paulatina disminución en el quehacer de Vázquez en Andalucía Occidental hasta su muerte en 1589. También tendrá lugar la desaparición de algunos de sus mejores discípulos y colaboradores como Jerónimo Hernández que morirá en 1586.

En la provincia de Sevilla, obras como el San Pablo de Écija ${ }^{10}$, la berruguetesca imagen del San Antonio Abad de Carmona ${ }^{11}$ o el crucificado de la Salud de Sanlúcar la Mayor ${ }^{12}$ han sido devueltos a la paternidad de Vázquez, o al menos atribuidos con bastante seguridad a él.

\section{Obras de Vázquez}

San Sebastián de la quinta Angustia de Carmona

El contrato del retablo mayor para la iglesia de San Francisco ${ }^{13}$ de Carmona, describe el concierto de Vázquez con "Iuan de Góngora de la Barrera, clérigo, presbitero beneficiado de la iglesia de Santiago de la Villa

10 Porres Benavides, 2009: 233-244. Porres Benavides/ García Rosell, 2010: 90-101.

11 Porres Benavides, 2009: 237-259.

12 En algunas referencias artísticas sobre Sanlúcar la Mayor, el Cristo se atribuía a Roque Balduque. No obstante, un historiador local, Enrique Ramos Sánchez-Palencia adelantó que puede ser obra de Juan Bautista Vázquez "el viejo". Consta en documentación notarial, fechada en el siglo XVI, que este imaginero cobró de la parroquia de San Eustaquio una cantidad por la obra de talla que he hecho para esa parroquia, sin especificar en qué consiste la obra de talla a que se refiere el documento; si imagen, retablo o alguna modificación. Silva Fernández, 2006:287.

${ }^{13}$ Fechado en Carmona a 11 de Noviembre de 1574. 


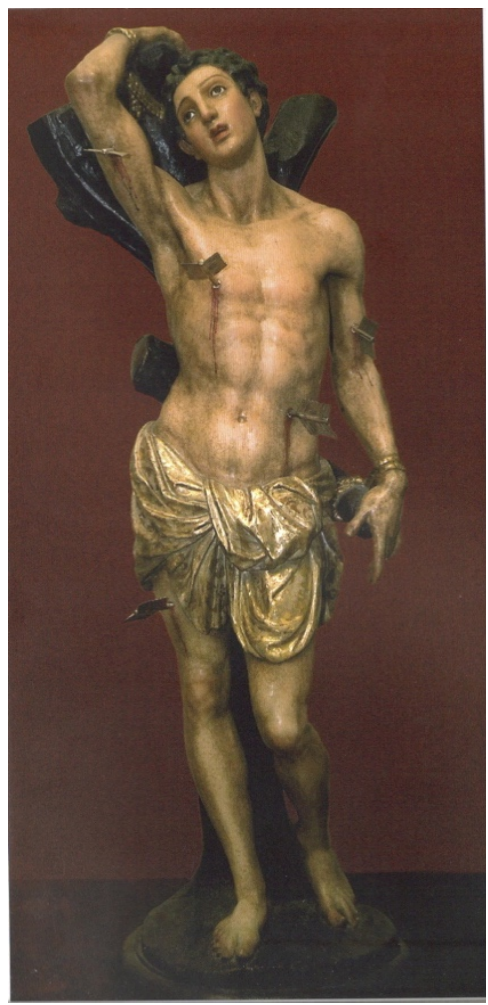

Fig.3 San Sebastián, Gaspar del Águila. Iglesia de San Sebastián, Marchena (Sevilla) Circa 1575.

de Carmona"14. En el documento se regulan los materiales que debían de utilizarse, y se le pedía que empleara pino de segura en las columnas, con objeto de que fuesen de una sola pieza, al utilizar un tronco para cada fuste. El retablo habría de ser "de borne de flandes seco y bien sazonado... eceto las colunas que seran de pino de sigura," al igual que la imaginería. En la escritura contractual, Vázquez se comprometía también a asentar personalmente el retablo en la iglesia, corriendo a cuenta de la comunidad solo los gastos de transporte y el andamiaje para montarlo.

Este retablo fue concebido por Vázquez como un tabernáculo mayor, y que sepamos, tendría en la calle central a San Sebastián, y arriba una figura de bulto "de más de medio relieve" de San Francisco. Encima tendría "el padre eterno echando la bendición” coronando el retablo.

Aparte, habría escenas de pintura al óleo en las calles laterales, que tendrían un apretado programa iconográfico con temas cristíferos, marianos y de la propia orden. Estas tablas pictóricas las realizaría el propio Vázquez u otros que subcontratara él, junto al dorado de la mazonería y la policromía de las esculturas ${ }^{15}$, con las figuras que fueren señaladas y pedidas por el reverendísimo padre guardián de la casa. La obra se debería acabar en 18 meses y el coste ascendería a mil ducados.

La obra fue encargada, como se ha comentado, para la iglesia del convento de San Sebastián o San Francisco, nombre popular de este, debido a que esta orden habitó el convento hasta la exclaustración. Parece que hasta el primer tercio del siglo XX se conservaban sus retablos. El mayor fue cedido a la parroquia de Cazalla de la Sierra, pero ya no se trataba del ejecutado por Vázquez, sino el realizado en el primer cuarto del XVII. El resto de imágenes se trasladaron al convento de la Concepción de Carmona.

Hemos identificado la imagen del San Sebastián que presidía el retablo mayor de la iglesia. Esta debió de permanecer en el retablo barroco que se efectúa en el siglo XVII. Tras la declaración de demolición de la iglesia en plena Guerra Civil y su traslado a Cazalla de la Sierra, algunas imágenes se llevaron hasta el cercano convento, también franciscano, de la Concepción.

\footnotetext{
${ }^{14}$ Muro Orejón, 1932:64-66.

15 Palomero Páramo, 1981: 173.
} 
En la década de los 90 del siglo pasado, cuando las monjas cierran y ponen a la venta dicho monasterio, algunas imágenes, que según las monjas "babian pertenecido a san Francisco", son entregadas a la hermandad de la Quinta Angustia, radicada en la capilla adyacente al convento de San Francisco o de San Sebastián desde 163416. La actual capilla fue levantada nuevamente en el XVIII, y allí se encuentra en un retablo neoclásico en el lado derecho o lado de la epístola de la iglesia.

La imagen (fig.1), algo menor del natural ${ }^{17}$, aunque atribuida por algunos historiadores a Gaspar del Águila ${ }^{18}$, corresponde a la tipología vazquiana. El santo de pie, como suele ser normal en su iconografía, se apoya en un árbol a cuyas ramas se encuentra atado. Presenta los atributos habituales de su martirio ${ }^{19}$, como son las flechas que tiene introducidas en su cuerpo.

En general tiene una complexión delgada, aunque fuerte sin estridencias, en donde remarca la caja torácica y algunos músculos del cuerpo. La imagen presenta una gran elegancia en su composición, quizás algo hierática. Esta tranquila postura, se rompe solo por el brazo derecho, que tiene levantado al estar atado por la muñeca a una rama alta. Este movimiento lo acompaña la pierna correspondiente, que se retrae hacia atrás delicadamente.

Tiene sudario corto y sencillo como en algunos de los crucificados de Vázquez, con la decoración de rayado hebreo, parece que la policromía es la original. Los pies que apoya en el suelo, presentan similitud con pies de obras seguras de Vázquez, destacando las falanges marcadas y alongadas (fig.2). La cabeza muy serena, mira hacia arriba como en contemplación de la divinidad, y el rostro algo magro, también recuerda otros santos realizados por el maestro. Así como su boca de pequeña apertura pero carnosa hace esa inflexión característica de Vázquez. El pelo corto, de rizados muy voluminosos y algo abstractos también se asemejan a los que presentan algunos niños de Vázquez.

Esta imagen de San Sebastián, originaria de la iglesia del convento del mismo título de Carmona, aclara algo del quehacer de Vázquez allí y ha enriquecido el corpus local del artista en dicha ciudad ${ }^{20}$.

16 Leiria, 2007: 62, 76.

${ }^{17}$ Mide $1^{\prime} 4 \mathrm{~m}$. x 0’5m. x0’45 m.

18 Villa Nogales/ Mira Caballos, 1993: 42. Los autores la identifican con un San Sebastián contratado por Gaspar del Águila para la vecina iglesia de San Pedro en 1592. Según lo capitulado en la escritura de adjudicación de capilla, Sebastián Pérez se comprometía con el mayordomo de San Pedro a «facer retablo e aliñar los que en ella ay». Unos meses después, el 4 de octubre de 1592, se concertaba con el gran escultor Gaspar del Águila para la ejecución de un tabernáculo e imagen de San Sebastián, con destino a su capilla del Sagrario y que debía entregar realizada «el primer día de Pascua», cobrando por todo ochocientos reales. Dichos autores identificaron correctamente un san Blas procedente de la iglesia del mismo nombre, como obra de Gaspar del Águila en 1576 ahora en San Bartolomé.

Para más confusión a esta atribución, tenemos la noticia de que en 1600 el escultor Matías de la Cruz concierta con el mayordomo de la hermandad de San Sebastián de la iglesia de San Francisco, una imagen de seis palmos de altura "sin la peaña con sus saetas de madera.. en dos meses y precio de 28 ducados" en López Martínez, 1932:.41. De hecho, esta atribución sale en algunas publicaciones como el blog de la parroquia de San Pedro y san Francisco "San Sebastián (II) - capilla san Francisco", Carmona lunes, 21 de febrero de 2011. http://sanpedrocarmona.blogspot.com.es/2011/02/san-sebastian-II-capilla-san-francisco.html. Creemos sin duda alguna que esta imagen es otra de la que nos referimos, quizás vicaria para salidas procesionales o cultos.

${ }^{19}$ Nació en Narbona (Francia) en el año 256, pero se educó en Milán. Fue militar del ejército romano. Como cristiano, ejercitaba el apostolado entre sus compañeros, visitando y alentando a otros cristianos encarcelados por causa de su religión. Acabó por ser descubierto y denunciado al emperador Maximiano que le condenó a morir asaeteado. Los soldados del emperador lo llevaron al Estadio, lo desnudaron, lo ataron a un poste, y lanzaron sobre él una lluvia de saetas, dándolo por muerto. Sin embargo, sus amigos se acercaron y, al verlo todavía con vida, lo llevaron a casa de Irene, que lo mantuvo escondido y le curó las heridas hasta que quedó restablecido.

Sus amigos le aconsejaron que se ausentara de Roma, pero Sebastián se negó rotundamente. Se presentó ante el emperador, quien, desconcertado, lo daba por muerto, y le reprochó enérgicamente su conducta por perseguir a los cristianos. Maximiano mandó que lo azotaran hasta morir, tirando su cuerpo en un lodazal. Los cristianos lo recogieron y lo enterraron en la Vía Apia, en la célebre catacumba que lleva su nombre. Murió en el año 288. Para saber más de este tema se puede consultar: Lanzuela Hernández: pp.231-258.

20 Villa Nogales/Mira Caballos, 1993: 129. Recordemos que continúa la obra del retablo mayor de Santa Maria, iniciado por Nufro de Ortega y unas labores en la iglesia de San Bartolomé que no se han conservado, aunque en dicha iglesia hay una santa Lucia que presenta características propias del autor. 


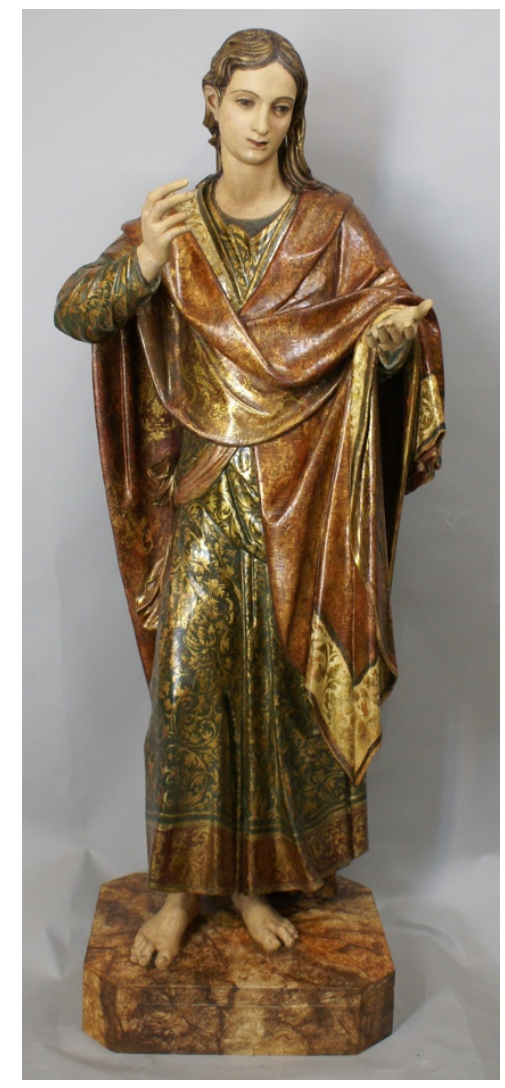

Fig.4. San Juan Evangelista. Iglesia del Dulce Nombre de Jesús. Sevilla. (C) Benjamín Domínguez Gómez.

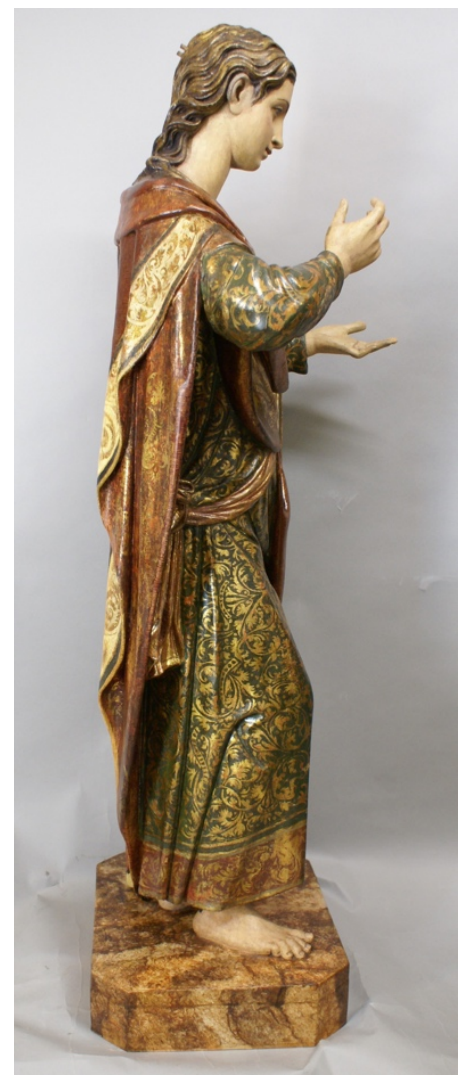

Fig.5. Por menor de perfil San Juan Evangelista. Iglesia del Dulce Nombre de Jesús. C) Benjamín Domínguez Gómez.

Tradicionalmente ha sido adscrita a Gaspar del Águila, cosa en absoluto descabellada ${ }^{21}$, pues como sabemos, éste fue discípulo de Vázquez, con quien se vino desde su Ávila natal, incluso llegando a realizar algunas obras e imágenes en mancomún como el San Pablo de Écija. Pero nada se dice de su colaboración en 1574 en este retablo, fecha en que creemos que ya se había independizado del taller de Vázquez. De hecho el San Sebastián (fig.3) que realiza para Marchena hacia 157522, tiene una

21 Al que además se le adjudican obras en Santa María de Carmona y Federico García de la Concha le atribuye el magnífico Cristo con la cruz a cuestas, hoy en el convento de franciscanas concepcionistas de Mairena del Aljarafe (Sevilla), pero proveniente de las concepcionistas de Carmona. También realizó para el mismo convento de San Francisco un retablo con la imagen de San Diego en 1589 y el propio patrón de la ciudad San Teodomiro en 1599.

22 Esta imagen de Marchena ha sufrido alguna intervención como la colocación de ojos de cristal en el siglo XIX por el escultor Gabriel de Astorga que sin duda ha modificado su expresión en Ramos Suarez, 2014: 5859. En esta misma iglesia de San Sebastián de Marchena, se encuentra un crucificado de tamaño casi natural que desgraciadamente ha pasado inadvertido para la crítica. Pertenecía a la hermandad de Ánimas de dicho templo, y de hecho a los pies del crucificado se disponen cuatro pequeñas imágenes de las ánimas del purgatorio. Está en una cruz plana y estilísticamente recuerda a las obras del tándem Vázquez-Vergara de Toledo como el Cristo para la catedral de aquella ciudad, desgraciadamente perdido en la última contienda. Las caderas se desplazan hacia la derecha provocándole cierta contorsión que no presentan otros crucificados de Vázquez. La imagen tiene una musculatura fuerte parecida el Cristo ya mencionado de Toledo, el de Tunja o al que se le atribuye del Amor, actualmente en el Viso del Alcor. El sudario corto y ceñido presenta la lazada suelta como el de Tunja. Los dedos índice y corazón de ambas manos se estiran como señalando. La cabeza, muy bella, tiene muchas analogías con obras de Vázquez. El cabello modelado de manera muy desdibujada al igual que la barba. La boca está entreabierta como muchos de sus crucificados. Por último los pies con esos dedos alongados y huesudos también recuerdan a otros crucificados como el de Burgos. También en la localidad del Garrobo se 
concepción algo diferente, mucho más dinámica y efectista, con un contraposto muy sensual, que la de Carmona no posee y una musculatura más marcada, el sudario además es más complejo y se anuda al centro haciendo una moña muy voluminosa. Hay que reconocer sin embargo, que el tratamiento del rostro, en especial de la boca, la nariz y rasgos generales sí se aproximan a la imagen carmonense.

Comparándola con otros santos de dicha iconografía, no tiene demasiado que ver con el existente en la parroquia de Salteras (Sevilla), más manierista y quizás relacionable con otras obras anónimas

conserva otra interesante imagen atribuida a Gaspar del Águila, fechable en el último tercio del XVI. Morales y otros, 1981: p. 574. 


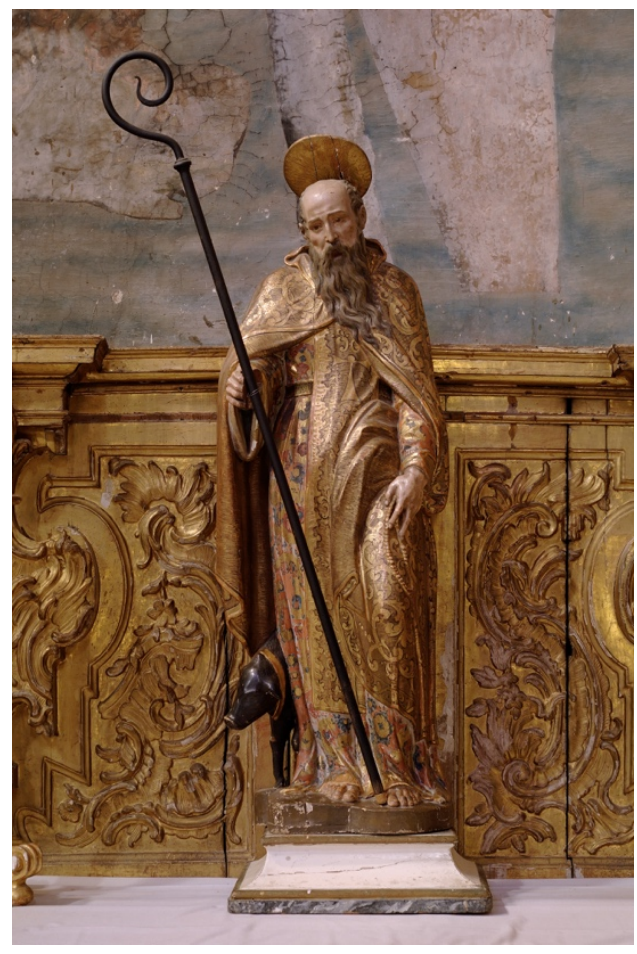

Fig.6. Imagen de San Antonio Abad. Iglesia de Santa Maria de Carmona (Sevilla). CJesús Porres Benavides

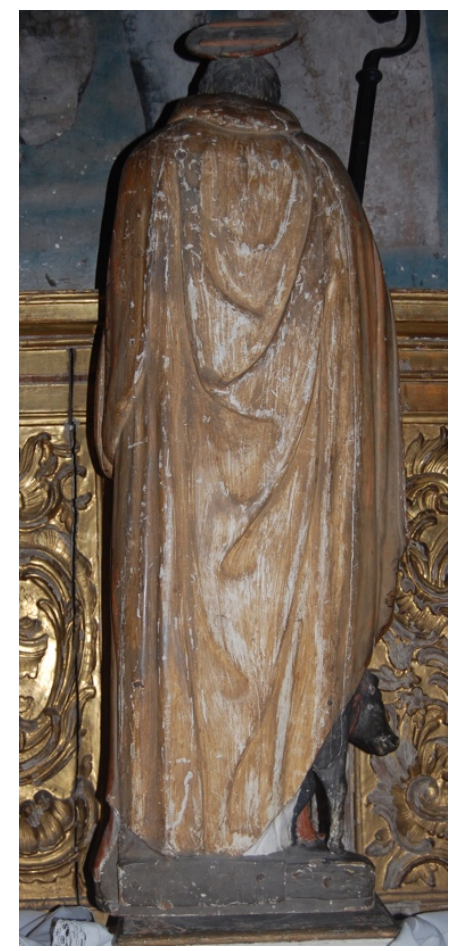

Fig.7. Reverso de la imagen de San Antonio Abad. Iglesia de Santa Maria de Carmona (Sevilla). CJesús Porres Benavides.

como el pequeño Cristo atado a la columna de la parroquia de Cantillana (Sevilla) ${ }^{23}$. El cuerpo de este santo dispone un bello contraposto, con la cadera girada hacia la derecha y la cabeza también, disponiendo una contorsión "serpentinata".

Otros santos de tema homónimo y que siguen algo la composición son el que realiza Diego Rodríguez, para Arequipa (Perú) en el último tercio del XVI, discípulo de Hernández y parece que del propio Vázquez, y emigrado a América. También similar es el San Sebastián de Huejotzingo (Méjico) realizado por Pedro Requena hacia 158524. Más evolucionado, sin embargo, sería el San Sebastián de la iglesia de San Bernardino en Xochimilco (Méjico) ${ }^{25}$.

\section{San Juan Evangelista}

En las dependencias de la hermandad de Vera Cruz, que ocupa hoy la iglesia del Dulce Nombre de Jesús, se encontraba una imagen de san Juan Evangelista, aunque en la reforma que tuvo a mediados del siglo XX fue convertido en una santa Lucía ${ }^{26}$, quizás por haber estado allí la hermandad del mismo título hasta los años $60^{27}$. Otros autores apuntan que originariamente podría haber sido

${ }^{23}$ De autor anónimo y fechable en el $2^{\circ}$ tercio del XVI.

24 Porres Benavides, 2014 A: 189.

25 Moyssen, 1966: pp. 4-7. En esta imagen Margarita Estella ha visto la mano de Vázquez junior, quizás por comparación con el realizado para la iglesia de la Anunciación sevillana. Estella Marcos, 1990: p.94

${ }^{26}$ Se tenía constancia de que había sido utilizada también como san Rafael, habiéndose colocado diferentes atributos iconográficos, según los casos.

27 Durante los años en los que la Organización Nacional de Ciegos (O.N.C.E.) celebraba sus actividades religiosas en esta capilla, permaneció la imagen en el altar mayor al menos hasta, la década de los cincuenta. La adaptación se resolvió colocándole la espada en la mano derecha y la bandeja con los ojos en su mano izquierda, atributos propios de su iconografía. Tras pasar por otros retablos cuando la imagen del Cristo de la Vera Cruz 


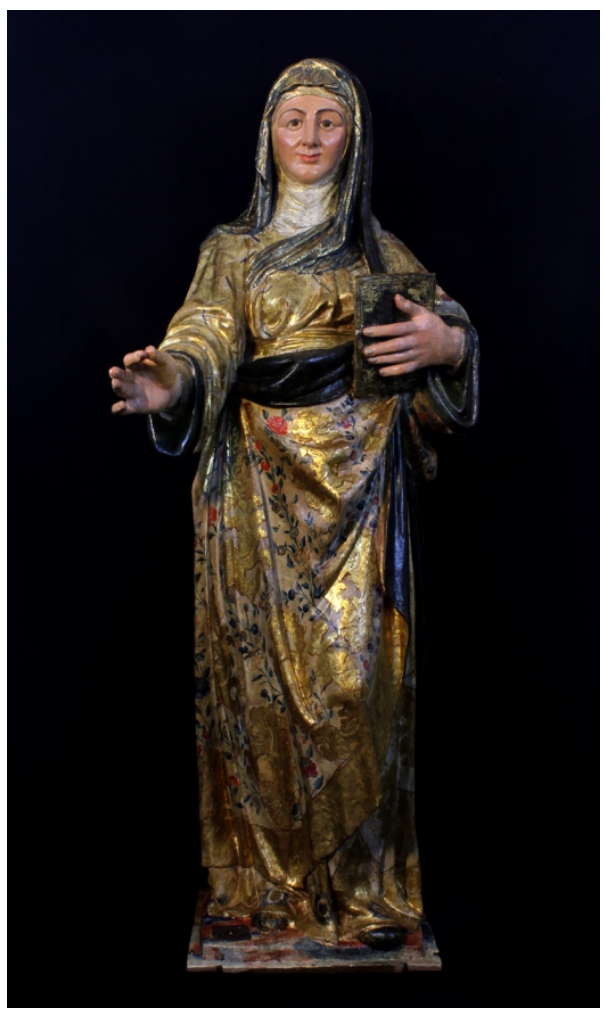

Fig.8. Santa Ana. Iglesia de Santa María de la Asunción de Aroche (Huelva) CJosé María Sánchez Vázquez.

una santa Bárbara, aunque morfológicamente no corresponde con una figura femenina. Ya hace unos años se estudió convenientemente el retablo donde se ubicó dicha imagen ${ }^{28}$ a raíz de la intervención que se le practicó. En dicho artículo se apuntó la posibilidad de que dicha imagen hubiera formado parte de este retablo y la relación con imágenes como el San Juan Evangelista de Acora ${ }^{29}$.

La obra (fig.4), sin duda, goza de los grafismos de Vázquez y tiene relación con esculturas realizadas por él, o en su órbita, como el ya comentado de Acora (Perú) con el que comparte la disposición de la cabeza y las manos. Aunque también por supuesto con algunas imágenes realizadas por el maestro como el San Juan evangelista que se ubica en el Calvario del retablo mayor de Santa María de Carmona, aunque con una disposición ligeramente diferente al interactuar con la Virgen a la que acompaña.

La imagen que nos ocupa pudo presidir el retablo, ya que estilísticamente y por sus medidas encaja y actualmente se ha colocado allí tras la restauración de ambas piezas. La madera en que está compuesta la imagen es cedro y los estofados de la vestimenta corresponden en su gran mayoría al s. $\mathrm{XVI}^{30}$. Observando el perfil (fig.5) podemos comprobar cómo fue hecha para retablo, debido a la poca profundidad que presenta sobre todo en la parte posterior.

Por lo que respecta a su iconografía original, si atendemos a los pocos elementos de juicio que tenemos, todo parece indicar que se trata del discípulo amado de Cristo. En primer lugar por la juventud que presenta su rostro, de la cual Pacheco nos refiere que ha de representarse "mozo" y "mancebo", de unos 22 años de edad; en actitud de portar en su mano el cáliz ${ }^{31}$, lo cual puede

pasó a presidir la capilla, se retiró del culto en 1988 y pasó a las dependencias interiores. Domínguez Gómez, 2015: 46

28 Porres Benavides/ Domínguez Gómez, 2012. Aunque la posible paternidad de la obra ya la apuntaba la profesora Fraga Iribarne en la publicación de la que fuera su tesis doctoral. Fraga Iribarne, 1993: p.56

29 Porres Benavides/ Domínguez Gómez, 2011: p.117.

${ }^{30}$ Domínguez Gómez, 2015: 45.

31 Sus atributos más constantes y característicos son el águila, la copa de veneno, el caldero de aceite hirviente y la palma del Paraíso. En los ciclos de los apóstoles tiene como emblema la copa envenenada, de la que escapa 
corresponderse por la disposición de los dedos. También por el colorido y disposición de los ropajes -verde y rojo- 32 que, aunque- Pacheco indica el blanco como el correspondiente a la túnica, como viene siendo habitual en la iconografía occidental desde época medieval- se representa, ataviado con túnica verde "ceñida" y manto rojo sobre los hombros. Los pies alargados y con las falanges muy pronunciadas recuerdan a los pies típicos de Vázquez.

Por la información que arroja el análisis organoléptico de la escultura, se evidencia que la imagen ha sufrido, al menos, dos intervenciones: la primera y más antigua que sustituyó la peana original por la actual y otra consistente en el "repintado" de los motivos vegetales del estofado de la túnica con "purpurina" o pintura dorada comercial, de una manera burda 33 .

\section{San Antonio Abad}

También en la localidad de Carmona se encuentra la imagen de San Antonio Abad (fig.6) que puntualmente cité en un artículo hace unos años y que se localiza debajo de la pintura mural de San Cristóbal ${ }^{34}$ en Santa María de Carmona. Por el análisis organoléptico que hemos realizado para la ocasión, se ha comprobado que la imagen es de madera, posiblemente cedro, se encuentra ahuecada y tiene la típica tapa posterior que cubre la totalidad de la imagen desde los hombros hasta los pies en la espalda que se encuentra adherida mediante colas y clavos de forja (fig.7). A pesar de este ahuecamiento presenta un gran peso para el volumen que tiene.

Es estilísticamente muy cercano a los modelos de Vázquez, cuya autoría es muy posible al haber realizado él el retablo mayor de dicha iglesia. Quizás se hubiera realizado previamente a la construcción de éste como prueba de la habilidad del escultor. El santo ${ }^{35}$ se encuentra de pie, en un pequeño contraposto, en el que adelanta la pierna izquierda, en donde a su vez descansa la mano que sujeta un rosario. El rostro magro girado del santo anciano y sus manos son de bastante calidad. El tratamiento de los cabellos y en especial las barbas alargadas y tratadas en mechones zigzagueantes de cierto barroquismo y tratados de una manera abstracta, herencia berruguetesca, las recrea el autor en otras imágenes como Dios Padres o incluso algunos apóstoles (como los que están en el mismo retablo mayor de la iglesia).

Vestido con túnica, escapulario (con la típica cruz de san Antonio) y capa, cuyo lado izquierdo se recoge elegantemente tras la mano que sostiene un rosario. Con la otra mano sostiene el típico cayado $^{36}$ (atributo habitual del santo, junto al cerdo que está a sus pies). En la imagen, a pesar del estofado rococó que presenta ${ }^{37}$, se aprecian los típicos rasgos del maestro, quizás todavía bajo el influjo de Berruguete, apreciable en la disposición y zonas como la barba muy barroca. Esto es comprensible pues la obra del retablo se puede fechar hacia 1563, una fecha temprana que todavía denota ese manierismo florentino propio del maestro de Paredes de Nava.

\section{Obras del círculo de Vázquez}

Santa Ana

el veneno en forma de dragoncillo. El atributo de la copa apareció tardíamente, en el siglo XIII. Esta con frecuencia tiene la forma de un cáliz donde, en lugar del dragón, encima del recipiente se representa una hostia. Según la tradición recogida por el pseudo-Isidoro de Sevilla, se había intentado envenenar a san Juan con un cáliz de la comunión (aparece como atributo en el siglo XIII) con un pequeño dragón alado símbolo de la fuerza del veneno saliendo de la copa. Vilaplana, 1995: 400.

32 López Aparicio, 2013.

33 Domínguez Gómez, 2015: 46.

34 Porres Benavides, 2009: 237-259.

35 Con unas dimensiones: alt. 1,27 mt. x anch. $46 \mathrm{~cm}$. x prof. $35 \mathrm{~cm}$.

${ }^{36} \mathrm{El}$ que presenta en la actualidad es uno metálico de factura moderna, aunque se observa en la mano restos del cayado en madera original.

37 Seguramente realizado en la segunda mitad del XVIII y en el que se dejó sin acabar la parte posterior, cuya preparación tiene una tonalidad marrón-ocre, debido a que se pensaba que no se iba a contemplar en su totalidad. 
Fig.9. Santa Barbará. Iglesia de Omnium Sanctorum (Sevilla). CJesús Porres Benavides.

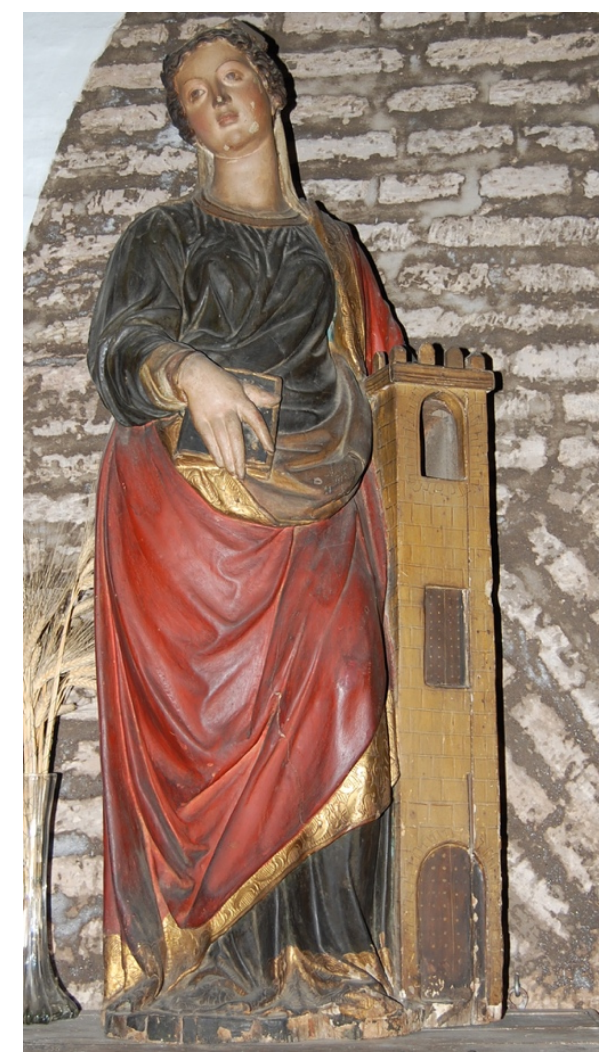

En la iglesia parroquial Santa María de la Asunción de Aroche se encuentra una imagen de Santa $\mathrm{Ana}^{38}$ de tamaño casi natural. Esta imagen (fig.8) habría que adscribirla cronológicamente en la segunda mitad del XVI y al entorno de Vázquez.

La imagen se encuentra erguida y frontal con una mínima flexión en su pierna izquierda, que le confiere un tímido contraposto acompañado con una curvatura hacia la izquierda. En el rostro sereno y frontal se dibujan los rasgos de la ancianidad, principalmente en el detalle de los pómulos tan pronunciados. En la mano derecha porta un libro por ser la santa madre-maestra y que enseña a leer a su hija María; en la izquierda sostendría un lirio. En la obra, aunque enmascarada en una restauración posterior del siglo XVIII que le habría afectado a su imagen exterior: encarnaduras y estofados en la vestimenta $^{39}$, se puede apreciar unas características propias del taller de Vázquez. Esa disposición en buso de la obra, el tratamiento delicado de los paños y el tratamiento de los pechos y la disposición del velo o toca ${ }^{40}$ sobre estos recuerda a obras seguras o atribuidas con fundamento.

En la iglesia de Consolación del Pedroso (Sevilla) hay una Santa Ana, sedente y de las denominadas triplex por estar con la Virgen y el Niño en su regazo. Esta Santa Ana se fecha en el segundo tercio del XVI y se relaciona con Vázquez, aunque también recuerda a las realizadas por Pesquera. Con esta última obra comparte algunas características como son las manos y la concepción del torso, aunque la disposición iconográfica sea diferente.

Sin duda la imagen desmerece de perfil, sobre todo por grandes desproporciones como el brazo derecho que parece portar un atributo; o la excesiva planitud de la parte trasera, en parte comprensible

${ }^{38}$ Se ha intervenido por los restauradores Paula María Campos Abejón y José María Sánchez Vázquez en el periodo 2015-16. Tiene unas medidas de 140 × 60 × $54 \mathrm{~cm}$. El soporte en que está realizada es pino y cedro (esta última para manos). Está ahuecada en su interior y cerrada con una tapa el reverso.

${ }^{39}$ Compuestas básicamente por piezas ornamentales doradas y rocallas, acompañados de rameados florales polícromos en el manto con su consiguiente cenefa dorada y labores de esgrafiado y picado de lustre en el resto como el velo o la túnica. Según los restauradores, hay restos de una policromía anterior debajo de la actual.

40 Por su condición de casada, Peinado Guzmán 2014; 205. 
al ser una obra concebida para un retablo. Tampoco ayuda esa cierta rigidez en el rostro y la excesiva amplitud de las manos; aun así, en general tiene calidad y se podría atribuir a la labor de algún seguidor de Vázquez como Miguel Adán o Gaspar del Águila¹.

Otra obra que tampoco podríamos considerar del maestro, pero sí de un seguidor cercano como el propio Jerónimo Hernández, es la Santa Bárbara de la iglesia de Omnium Sanctorum de Sevilla ${ }^{42}$. Esta imagen (fig.9) que se encuentra actualmente en una de las capillas de la nave del Evangelio, parece que proviene de una iglesia de Carmona u Osuna en los años 40 tras la quema de dicha iglesia en los acontecimientos de 1936. Entonces, la iglesia pierde prácticamente todos sus retablos e imágenes, salvo las que se guardaron escondidas. Dentro del programa de recuperación de iglesias arrasadas, el párroco, que al parecer formaba parte de la Comisión de Arte de la diócesis hispalense, consigue retablos y enseres de distintos puntos de la provincia.

La santa se encuentra erguida, con una torre que se apoya en el suelo como atributo personal y presenta un leve contraposto, adelantando la pierna derecha, mientras que la cadera se gira levemente al igual que la cabeza que se gira hacia su izquierda. Presenta el cuello alargado parecido a otras imágenes del entorno de Vázquez y la forma del plegado de los paños la acerca a otras imágenes del autor como la Virgen de las Fiebres, o incluso la forma tan sensual de marcar los pechos que repite en otras composiciones como el Giraldillo. La mano izquierda que sostiene delicadamente el libro, y que grácilmente compone con el detalle de separar el dedo índice de los otros tres, recuerdan a otras manos femeninas del autor. También por detalles como el tocado del pelo recogido y el velo que, discretamente parece partir del tocado, recuerda a otras composiciones que se le pueden encuadrar en un artista muy cercano a Vázquez: como la Santa Rufina de la actual colegial del Salvador, en especial el tocado y el volumen de los pechos y el delicado contraposto.

Esta imagen de la iglesia del Salvador tiene una repolicromía en el siglo XIX que la desvirtúa algo de su configuración original. Gómez Piñol la asocia a la labor del mejor discípulo de Vázquez, Jerónimo Hernández, situándola en la década de 1580 y poniéndola en relación con otras obras del artista como la desaparecida Virgen de Villalba del Alcor o la Virgen del Rosario del convento de Madre de Dios (Sevilla).

Recordemos por último que Jerónimo Hernández contrató en 1586 en colaboración con Núñez Delgado un retablo con esta advocación, y se supone que contendría las imágenes de las santas, para el monasterio sevillano de la Concepción. La santa Rufina, con ese contraposto, motiva una amplísima curva en la cadera izquierda -un verdadero "dehanchement" clásico subrayado por el predominio de los largos pliegues que surcan la blanda anatomía-. Gómez Piñol dice de ellas que "policromadas con tonos escasamente atractivos, se percibe, no obstante la mórbida calidad, el "contraposto" compositivo y los rasgos de idealización de la belleza femenina emanados del clasicismo renacentista italiano".

\section{Dios Padre}

Recientemente identificado, está el relieve de Dios Padre ${ }^{43}$ (fig.10) en una colección particular de Sevilla. Se trata de un alto relieve que está inscrito en un óvalo o tarja en una superficie rectangular. Dios Padre está de medio cuerpo, en la mano izquierda, sostiene la bola del mundo y la derecha está en actitud de bendecir. Destaca la apostura de su composición y recuerda a otros Dios Padre y a esculturas de santos en la órbita de Vázquez; aunque también hay que reconocer en esta imagen influencias de Jerónimo Hernández, y quizás, haber formado parte de un retablo desmontado de este autor. Así tenemos por ejemplo que el Dios Padre que iba en el ático del retablo del monasterio de las Dueñas de Sevilla va en el óvalo del remate. No se sabe su procedencia, aunque seguramente formara parte de un retablo de alguna iglesia sevillana.

\footnotetext{
${ }^{41}$ Quien realizó alguna imagen con esta iconografía.

42 Porres Benavides, 2010: 164 .

43 Tiene unas dimensiones de $102 \times 69 \mathrm{~cm}$.
} 


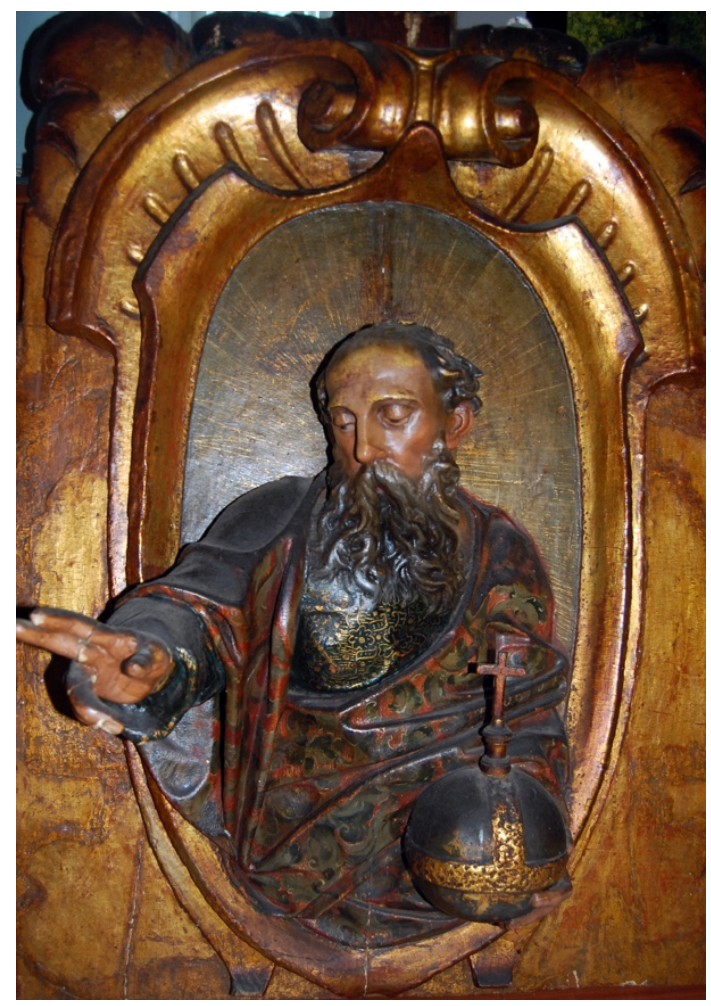

Fig.10. Dios Padre. Colección particular sevillana CJesús Porres Benavides.

Otra obra, que aunque comentada ya, y que habría que encuadrar en la producción de algunos discípulos de Vázquez (quizás Miguel Adán), es la Virgen del Rosario de la iglesia de Santo Domingo $^{44}$ de Sanlúcar de Barrameda (Cádiz) ${ }^{45}$.

Estas obras que atribuimos a la producción del maestro, enriquecen el estudio de Vázquez en su etapa sevillana (1560-1588). Son obras de imaginería, talladas en madera, policromadas y estofadas en sus partes de vestimenta. Se pueden fechar en un arco cronológico de una quincena de años (15651580) El San Antonio sería el más antiguo (fechable hacia 1563), el San Sebastián hacia 1574 y el San Juan entendemos que se realizaría simultáneamente con del retablo del Dulce Nombre ${ }^{46}$,a principios de la década de los 70 .

Todas las obras pertenecen al periodo álgido del maestro, que hacia 1580 empieza a notar cierta decadencia en su taller reservándose para encargos como los relieves de la Sala Capitular sevillana. En esta década de los 80 se observa una paulatina disminución en el quehacer de Vázquez, entrando en competencia con sus discípulos más aventajados.

${ }_{4}$ Dicho monasterio dominico fue fundado en la primera mitad del siglo XVI por el V duque de MedinaSidonia, Alonso Pérez de Guzmán y Zúñiga y su mujer, Ana de Aragón. Sin embargo, su construcción se realizó más tarde, entre los años 1558 y 1570 a expensas de la condesa de Niebla. Sin duda el patronazgo de la casa ducal hace más fuerte esta hipótesis, pues como hemos visto Vázquez y Núñez Delgado trabajan al servicio del VII Duque don Alonso Pérez de Guzmán para sus palacios de Sevilla y el de Sanlúcar de Barrameda en los años 1575 y 1576. Es interesante el dato de que la iglesia fuese trazada por Hernán Ruiz II, con quien Vázquez trabajaba a menudo. Cruz Isidoro ha puesto en relación un cristo atado a la columna que se encuentra en dicha iglesia al entorno de Vázquez. También sabemos que trabajó allí Miguel Adán, discípulo de Vázquez, realizando el retablo mayor, contratado en 1592 y que por tanto podrían ser obras de él, aunque demuestren una clara filiación con el maestro. Así tiene cierto parecido con la Virgen del Rosario que hace Adán para la iglesia de Palomares del Río (Sevilla) en 1588.

45 Porres Benavides, 2010; 164.

46 El contrato se hace el 15 de Mayo de 1571, por el cual Juan Bautista Vázquez se compromete con Alonso de Barrionuevo y con el Doctor Juan de Castañeda que actúa en su nombre a realizar un retablo para la Capilla que el mencionado Alonso de Barrionuevo poseía en el Convento del Dulce Nombre de Jesús. (Oficio 9, año 1571, libro no 20 105-15, n2 .17616). 


\section{Bibliografía}

Alonso Moral, R.:: "La producción de escultura en barro del Manierismo al primer naturalismo: Gaspar Núñez Delgado y los hermanos García” en La Escultura del primer naturalismo en Andalucía e Hispanoamérica (1580-1625) c. de Lázaro Gila Medina, (2010), p. 336.

Bernales Ballesteros, J. y García de la Concha, F.: Imagineros andaluces en los siglos de oro. Sevilla, (1986), p. 29.

Cruz Isidoro, F.: "El belén de los Guzmanes de 1576: un portalejo de Juan Bautista Vázquez "El Viejo" y Gaspar Núñez Delgado”, Extracto de la conferencia. En: Actas del IV Encuentro Regional de Belenistas, Auditorio de la Merced, Sanlúcar de Barrameda, (2006).

Cruz Isidoro, F.: “Juan Bautista Vázquez “el viejo” y Gaspar Núñez Delgado al servicio del VII duque de Medina Sidonia (1575-1576)". En: Archivo Español de Arte. Volumen LXXXV N. ${ }^{\circ} 339$ julio septiembre, Madrid, (2012).

Domínguez Gómez, B.: "Intervenida la imagen de San Juan del retablo renacentista”. En: Vera Cruz, 2015 Boletín de la hermandad de Vera Cruz. Sevilla, (2015), p. 46.

Estella Marcos, M.: "Sobre escultura española en América y Filipinas". En Relaciones artísticas entre España y América. Consejo Superior de Investigaciones Científicas. Centro de Estudios Históricos. Departamento de $\mathrm{H}^{\mathrm{a}}$ del Arte "Diego Velásquez", Madrid, (1990), p.94.

Fraga Iribarne, $\mathrm{M}^{\mathrm{a}}$ L.: Conventos Femeninos desaparecidos. Sevilla -Siglo XIX. Ediciones Guadalquivir, Sevilla, (1993), p.56

Gila Medina L. y Herrera García, F. J.: "Escultores y esculturas en el Reino de Nueva Granada (Colombia)". En La Escultura del primer naturalismo en Andalucía e Hispanoamérica (1580-1625) coordinación de Lázaro Gila Medina, Granada, (2010).

Lanzuela Hernández, J.: “Una aproximación al estudio iconográfico de san Sebastián”. En Studium. Revista de Humanidades 12, (2006), pp.231-258.

Leiria, A.: Quinta Angustia de Carmona. Carmona, (2007), pp.62, 76.

López Aparicio, M.: "El valor de la imagen religiosa durante la Contrarreforma. El Apostolado del Monasterio de San Victorián”.En www http://museodiocesano.es/2013/09/10/el-valor-de-laimagen-religiosa-durante-la-contrarreforma-el-apostolado-del-monasterio-de-san-victorian/ (2013).

López Martínez, C.: Desde Martínez. Montañés hasta Pedro Roldán. Notas para la Historia del Arte. Sevilla, Imprenta de Rodríguez, Jiménez y $C^{\mathrm{a}}$, (1932), p.41.

Moyssen, X.: "El San Sebastián de Xochimilco" en Boletín del Instituto Nacional de antropología e Historia. México 24, (1966), pp. 4-7.

Morales, A. y otros.: Guía Artística de Sevilla y su Provincia .Excma. Diputación provincial de Sevilla. Sevilla, (1981), p. 574.

Muro Orejón, A.: "Artífices sevillanos de los siglos XVI y XVII". Documentos para la historia del arte en Sevilla. Vol. IV. Sevilla, (1932), pp.64-66.

Palomero Páramo, J.: El retablo sevillano del Renacimiento. Análisis y evolución (1560 -1629) Sevilla, (1981), p.173.

Palomero Páramo, J.: “el contrato de aprendizaje de Jerónimo Hernández con Juan Bautista Vázquez El viejo" en Archivo Hispalense. no 196. Sevilla, (1981), pp. 139-142.

Peinado Guzmán, J. A.: "La iconografía de Santa Ana Triple. Su casuística en el arzobispado de Granada”. Revista del CEHGR. núm. 26. (2014), pp. 201-222.

Porres Benavides, J.: "La imagen de San Pablo de Écija, algunas pistas sobre su autoría" en actas de las VII Jornadas de Protección del patrimonio Histórico de Écija. Écija, (2009), pp. 233-244.

Porres Benavides, J.: “Juan Bautista Vázquez y el retablo de Santa María de Carmona” en Archivo Hispalense. $\mathrm{n}^{\circ}$ 279-28, (2009), pp. 237-259.

Porres Benavides, J. y García Rosell, C.: "La revisión documental en el estudio histórico- artístico: la nueva atribución del patrón de Écija”. En PH. IAPH. N. 76. Noviembre, (2010), pp.90-101.

Porres Benavides, J.: "Imágenes marianas en la obra de Bautista Vázquez", Miriam, revista mariana. Sevilla. (2010). 
Porres Benavides, J. y Domínguez Gómez, B.: "Un retablo de Bautista Vázquez en el convento del Dulce Nombre de Jesús". En Actas del congreso del centenario del Laboratorio de Arte. Sevilla, (2011), p.117.

Porres Benavides, J. y Domínguez Gómez, B.: "Proceso evolutivo y restauración en un retablo de Bautista Vázquez" en las actas de las jornadas del grupo de trabajo de retablos tituladas Estructuras y sistemas constructivos en retablos: estudio y conservación organizada por el grupo español del IIC. Valencia. (2012).

Porres Benavides, J. A: "Bautista Vázquez "el Viejo" y su escuela en los antecedentes del barroco Hispanoamericano". En: Actas del congreso internacional del Barroco. Arica 2013. Edit. en La PazBolivia, (2014), pp. 182-194.

Porres Benavides, J. A.: La técnica en Juan Bautista Vázquez el Viejo. Helvia: Repositorio Institucional de la Universidad de Córdoba http://hdl.handle.net/10396/12216 (2014).

Ramos Suarez, M.A.: La parroquia de San Sebastián Mártir de Marchena. Egondi impresores, (2014), pp.58-59.

Rokiski Lazaro, Ma L.: Escultores del siglo XVI en Cuenca. Diputación provincial de Cuenca, (2010), p. 27.

Silva Fernández, J. A.: Noticias histórico-artísticas en el Archivo de Protocolos notariales de Sanlúcar la mayor, 1550-1600”. Trabajo de Investigación Doctoral. Inéd., (2006), p. 287.

Valiñas López, F. M.: "Historiografía y fortuna crítica: Granada" en La Escultura del primer naturalismo en Andalucía e Hispanoamérica (1580-1625) coordinación de Lázaro Gila Medina. Granada, (2010), p.27.

Villa Nogales, F. y Mira Caballos, E.: Documentos inéditos para la Historia del Arte en la provincia de Sevilla. Siglos XVI-XVIII. Sevilla, (1993), pp. 42,129.

Vilaplana, D.: "Iconografía de los santos Juanes en el arte valenciano" Saitabi: revista de la Facultat de Geografia i Història. No. 45, (1995), p. 400. 